\title{
Formononetin Inhibits Migration and Invasion of MDA-MB-231 and 4T1 Breast Cancer Cells by Suppressing MMP-2 and MMP-9 Through PI3K/AKT Signaling Pathways
}

Authors

Affiliations

\author{
R. Zhou ${ }^{1 *}$, L. Xu ${ }^{2 *}$, M. Ye ${ }^{3}$, M. Liao ${ }^{3}$, H. Du ${ }^{1}$, H. Chen
}

${ }^{1}$ Department of Chest and Breast Surgery, Xiamen Hospital of Traditional Chinese Medicine, Fujian University of Traditional Chinese Medicine, Xiamen, P. R. China

Department of Orthopedic Oncology, Changzheng Hospital, Second Military Medical University, Shanghai, P. R. China Department of Breast Surgery, Longhua Hospital, Shanghai University of Traditional Chinese Medicine, Shanghai, P. R. China

Key words
formononetin
breast cancer
migration
PI3K/AKT
matrix metalloproteinases

received 19.09.2013 accepted 05.05.2014

Bibliography DOI http://dx.doi.org/ 10.1055/s-0034-1376977 Published online:

June 30, 2014

Horm Metab Res 2014;

46: 753-760

(c) Georg Thieme Verlag KG Stuttgart · New York ISSN 0018-5043

Correspondence

H. Chen

Department of Breast Surgery

Longhua Hospital

Shanghai University of

Traditional Chinese Medicine

725 South Wan-Ping Road

Shanghai 200032

P. R. China

Tel.: + 86/21/64385700

Fax: + 86/21/643 98310

chhfluk@126.com

\begin{abstract}
$\nabla$

Formononetin is a naturally existing isoflavone, which can be found in the roots of Astragalus membranaceus, Trifolium pratense, Glycyrrhiza glabra, and Pueraria lobata. It was found to be associated with inhibition of cell proliferation and cell cycle progression, as well as induction of apoptosis in various cancer cell lines. However, the effect of formononetin on breast cancer cell metastasis remains unclear. In this study, we examined the effect of formononetin on the migration and invasion of breast cancer cells MDA-MB-231 and 4T1 in vitro and in vivo. Our data demonstrated that formononetin did not effectively inhibit the cell viability of MDAMB-231 and 4T1 in $24 \mathrm{~h}$ with the concentration lower than $160 \mu \mathrm{mol} / \mathrm{l}$. When treated with nontoxic concentration of formononetin, the
\end{abstract}

\section{Introduction}

\section{$\nabla$}

Breast cancer is the most common malignancy among women worldwide. Each year, an estimated nearly 1.4 million patients are diagnosed with breast cancer globally with more than 450 000 deaths each year [1]. Approximately $10-20 \%$ of breast cancer cases are in the category of triple-negative phenotype, namely the absence of estrogen receptor- $\alpha$, progesterone receptor, or amplification of epidermal growth factor receptor [2]. Patients with triple-negative breast cancer have a very poor disease-free survival because these tumors are aggressive and associated with a high rate of metastasis compared with other types $[3,4]$.

Metastasis is a multistep process, which includes detachment of cancer cells from primary tumor, migration, adhesion, and invasion of cancer cells

${ }^{*}$ R. Zhou and L. Xu contributed equally to this study and should be considered as first co-authors. migration and invasion of MDA-MB-231 and 4T1 cells were markedly suppressed by wound healing assay, chamber invasion assay, and in vivo mouse metastasis model. In vitro, formononetin reduced the expression of matrix metalloproteinase-2 (MMP-2), MMP-9 and increased the expression of tissue inhibitor of metalloproteinase-1 (TIMP-1) and TIMP-2. Furthermore, the immunofluorescence and immunoblotting assays indicated that formononetin was very effective in suppressing the phosphorylation of Akt and PI3K. Collectively, these results suggest that formononetin inhibited breast cancer cell migration and invasion by reducing the expression of MMP-2 and MMP-9 through the PI3K/ AKT signaling pathway. These findings demonstrate a potentially new therapeutic strategy of formononetin as anti-invasive agent for breast cancer. into the blood or lymphatic vessels. The help of matrix metalloproteinases (MMPs) is required for extravasation out of the vessel, leading to the movement of cancer cells to the target tissue. Among all MMPs, MMP-2 and MMP-9, known as key enzymes in the degradation of type IV collagen, are overexpressed in breast cancer cells $[5,6]$ and their elevated expression has been associated with poor prognosis [7]. Thus, MMPs could work as pivotal targets for suppressing breast cancer invasion and metastasis, and the inhibition of MMPs may have considerable advantages in cancer therapy [8].

The discovery of novel compounds with low toxicity and excellent potential for cancer chemoprevention or treatment is an important step of cancer therapy development. Formononetin (7-hydroxy4'-methoxyisoflavone), an herbal isoflavone, is a major compound in the roots of Astragalus membranaceus, Trifolium pratense, Glycyrrhiza glabra, and Pueraria lobata. It has been proved to have immunomodulatory, antitumorigenic, hypolipi- 
demic, antioxidant, antiviral, cardioprotective, and estrogenic activities [9-15]. Moreover, formononetin exhibits cytotoxic activity on LNCaP and PC-3 (prostate cancer) [16], MDA-MB-435 and MCF-7 (breast cancer) [17,18], HuH-7 (live cancer) [19], SGC-7901 (gastric cancer) [12], as well as HeLa (cervical cancer), and HCT-116 (colon cancer) [20] cancer cell lines. Treatment of human breast cancer cells (MCF-7) with formononetin led to a significant decrease in cyclin D1 protein and gene expression, which was found to be associated with IGF1/PI3K/Akt pathways [17]. In addition, numerous studies have revealed that formononetin inhibits growth in various cancer types in vivo [17,20,21].

However, it remains unclear whether formononetin will be effective in inhibiting breast cancer cell metastasis. MDAMB-231 triple-negative breast cancer cell, a highly metastatic human breast carcinoma cell line, is derived from a metastatic plural effusion fluid and has been widely used as a model for studying breast cancer metastasis [22]. The 4T1 breast cancer cells with high propensity of metastasis were isolated from a spontaneous mammary tumor of a Balb/cC3H mouse. When these cells were transplanted into mammary pads of Balb/c mice, they formed tumors and metastasize spontaneously to tissues, such as the lung, the liver, and bones, thus providing an excellent model for examining the mechanisms of breast cancer metastasis $[23,24]$. Therefore, the objective of the study was to explore whether formononetin inhibited the migration and invasion of MDA-MB-231 and 4T1 breast cancer cells, and to further elucidate the underlying mechanism.

\section{Materials and Methods}

$\nabla$

\section{Materials}

Formononetin was purchased from Phytomarker Ltd. (Tianjin, China). It was dissolved in dimethyl sulfoxide (DMSO) and stored at $4{ }^{\circ} \mathrm{C}$ for further use. Penicillin, streptomycin, phosphate-buffered saline (PBS), trypsin-EDTA, DMEM, RPMI 1640, and fetal bovine serum (FBS) were obtained from Invitrogen (Carlsbad, CA, USA). 3-(4,5-Dimethylthiazol-2-yl)-2,5-diphenyltetrazolium bromide (MTT) and 4,6-diamidino-2-phenylindole (DAPI) were purchased from Sigma (St. Louis, MO, USA). Invasion chamber and matrigel were obtained from BD transduction Laboratories (Hercules, CA, USA). Trizol reagent, QuantiTect Reverse Transcription Kit and QuantiTect SYBR Green RT-PCR Kit were purchased from Qiagen Sciences (Germantown, MD, USA). Fluorescein isothiocyanate (FITC)-labeled secondary antibody was obtained from Invitrogen (Carlsbad, CA, USA). Antibodies against MMP-2, MMP-9, TMIP-1, TMIP-2, AKT, PI3K, ERK, JNK, phospho-AKT, phospho-PI3K, phospho-ERK, phospho-JNK, and $\beta$-actin were purchased from Cell Signaling Technology (Danvers, MA, USA). Goat anti-rabbit and goat anti-mouse peroxidase conjugated secondary antibodies were purchased from Bio-Rad (Hercules, CA, USA).

\section{Cell culture}

The human breast cancer cell line, MDA-MB-231, luciferase positive breast cancer cell (adenocarcinoma, mammary gland, further referred to as MDA-MB-231-luc) was obtained from Caliper Life Science (Hopkinton, MA, USA). Cells were cultured in DMEM medium supplemented with $10 \%$ FBS, $1 \mathrm{mmol} / 1$ sodium pyruvate, $0.1 \mathrm{mmol} / \mathrm{l}$ nonessential amino acids, and antibiotics (50 IU/ $\mathrm{ml}$ penicillin and $50 \mu \mathrm{g} / \mathrm{ml}$ streptomycin) at $37^{\circ} \mathrm{C}$ in a humidified atmosphere of $5 \% \mathrm{CO}_{2}$. The media was changed every 2 or 3 days.
Cells were detached with $0.05 \%$ trypsin-EDTA in PBS. The 4T1 cells were purchased from ATCC (Manassas, VA, USA). The cell line was cultured in RPMI 1640 medium supplemented with $10 \%$ FBS, $2 \%$ HEPES, $2 \%$ sodium pyruvate, and $1 \%$ penicillinstreptomycin antibiotic mixture. The cells were cultured according to the protocol provided by the ATCC company.

\section{Cell growth inhibition assay}

Cell viability was measured by the MTT assay. MDA-MB-231-luc and 4T1 cells were seeded into 96-well plates and cultured at a density of $5 \times 10^{3}$ cells per well. After $24 \mathrm{~h}$ of incubation, the cells were treated with vehicle $(0.1 \%$ DMSO) or a series of concentrations of formononetin for $24 \mathrm{~h}$. MTT solution was added to each well $(1.2 \mathrm{mg} / \mathrm{ml})$ and incubated for $4 \mathrm{~h}$. The concentration of MTT-formazan product dissolved in DMSO was estimated by measuring absorbance at $490 \mathrm{~nm}$ in an absorbance microplate reader.

\section{Wound-healing assay}

Cells were seeded in $1 \times 10^{5}$ cells $/ \mathrm{ml}$ and grown to $80-90 \%$ confluence in a 12 -well plate at $37^{\circ} \mathrm{C}, 5 \% \mathrm{CO}_{2}$ incubator. The monolayers were scratched with a $10 \mu$ sterile pipette tip, washed twice with PBS to remove floating cell debris, and then replaced with complete DMEM. MDA-MB-231-luc and 4T1 cells were treated with formononetin $(0,2.5,5,10,20$, and $40 \mu \mathrm{mol} / \mathrm{l})$ and incubated for $12 \mathrm{~h}$. Cell migration into the wound area was photographed under an inverted microscope. Migrated cells across the blue lines were calculated in 6 random fields from each triplicate treatment, and the data were presented as mean \pm SD.

\section{Cell invasion assay}

The invasive abilities of MDA-MB-231-luc and 4T1 cells were tested using cell invasion chamber kit. In brief, cells were treated with various concentrations of formononetin. After $12 \mathrm{~h}$, cells were detached by tryspin and resuspended in a serum-free $\operatorname{DMEM}\left(5 \times 10^{4}\right.$ cells $\left./ 100 \mu \mathrm{l}\right)$. The cells were seeded into the upper chamber of Matrigel-coated filter and a DMEM or RPMI 1640 containing $10 \%$ FBS of $500 \mu$ l was added to the lower chamber. The chamber was incubated $37^{\circ} \mathrm{C}$ for $6 \mathrm{~h}$. At the end of incubation, the noninvading cells in the upper surface of the filter membrane were carefully removed with a cotton swab. The invading cells on the lower surface of the filter membrane were fixed with $4 \%$ paraformaldehyde for $10 \mathrm{~min}$ and stained with crystal violet for $10 \mathrm{~min}$ and rinsed with water. The invasive cells on the lower surface of filter membrane were counted with a light microscope.

\section{Western blot analysis}

After treatment with various doses of formononetion for $12 \mathrm{~h}$, the MDA-MB-231-luc and 4T1 cells were lysed with RIPA buffer containing protease and phosphatase inhibitors. The protein concentrations were measured with a BCA kit (Beyotime, China). Equal amounts of protein were separated by sodium dodecyl sulfate-polyacrylamide gel electrophoresis (SDS-PAGE) and transferred to a polyvinylidene fluoride (PVDF) membrane. The membrane was blocked with a solution containing $5 \%$ nonfat dry milk TBST buffer (20 mM Tris- $\mathrm{HCl}$, pH 7.4, $150 \mathrm{mM} \mathrm{NaCl}$, and $0.1 \%$ Tween 20 ) for $1 \mathrm{~h}$. The indicated primary antibodies were incubated overnight at $4{ }^{\circ} \mathrm{C}$, washed, and monitored by immunoblotting using a DyLight 800 -conjugated secondary antibody. 
The membrane was scanned using a LI-COR Infrared Imaged Odyssey (Gene Company Limited).

\section{Real-time quantitative PCR}

MDA-MB-231-luc and 4T1 cells were treated with different concentrations of formononetin for $12 \mathrm{~h}$ and total RNA was isolated using the Trizol reagent according to manufacturer's protocol. The RNA concentrations were quantified with the Qubit Fluorometer. Real Time PCR (RT-PCR) was carried out using $1 \mathrm{ng}$ of total RNA, which was reverse transcribed into complementary DNA using the QuantiTect Reverse Transcription Kit according to the manufacturer's instructions. Quantitative RT-PCR was performed using the QuantiTect SYBR Green RT-PCR Kit. The PCR protocol conditions were as follows: HotStar Taq DNA polymerase was activated at $95^{\circ} \mathrm{C}$ for $2 \mathrm{~min}$, followed by 40 cycles at various temperatures/times (i.e., $94^{\circ} \mathrm{C}$ for $15 \mathrm{~s}, 60^{\circ}$ for $30 \mathrm{~s}$, and $72^{\circ} \mathrm{C}$ for $30 \mathrm{~s}$ ). At the end of the amplification period, melting curve analysis was done to confirm the specificity of the amplicon. Fold-changes of genes after treatment with different concentrations of formononetin were calculated by normalizing the $\mathrm{Ct}$ values to the GADPH internal control. The sequences of the primer pairs in this experiment were as follows: human GAPDH, 5'-GGCATCTTGGGCTACACT-3' (forward), 5'-GCCGAGTTGGGATAGGG-3' (reverse); human MMP-9, 5'-GGGACGCAGACATCGTCATC-3' (forward), 5'-TCGTCATCGTCGAAATGGGC-3' (reverse); human MMP-2, 5'-CTTCCAAGTCTGGAGCGATGT-3' (forward), 5'-TACCGTCAAAGGGGTATCCAT-3' (reverse); human TIMP-1, 5'-CTTCTGCAATTCCGACCTCGT-3' (forward), 5'-CCCTAAGGCTTGGAACCCTTT-3' (reverse); human TIMP-2, 5'-AAGCGGTCAGTGAGAAGGAAG-3' (forward), 5'-CACACACTACCGAGGAGGG-3' (reverse). Mouse GAPDH, 5'-GGCCTTCCGTGTTCCTAC-3' (forward), 5'-TGTCATCATACTTGGAGGTT-3' (reverse); mouse MMP9, 5'-TGTTCCCGTTCATCTTTGAG-3' (forward), 5'-ATCCTGGTCAT AGTTGGCTGT-3' (reverse); mouse MMP-2, 5'-AACTTCCGATTATC CCATGAT-3' (forward), 5'-GGCCAGTACCAGTGTCAGTA-3' (reverse); mouse TIMP-1, 5'-CAGTAAGGCCTGTAGCTGTGC-3' (forward), 5'-AG GTGGTCTCGTTGATTTCTG-3' (reverse); mouse TIMP-2, 5'-GGAATGACATCTATGGCAACC-3' (forward), 5'-GGCCGTGTAGATAAACTCGAT-3' (reverse).

\section{Immunofluorescence analysis}

MDA-MB-231-luc cells on coverslips were washed twice with PBS and fixed by $4 \%$ paraformaldehyde at $4{ }^{\circ} \mathrm{C}$ for $10 \mathrm{~min}$. Permeabilization of the cells was performed by incubating the cells with $0.1 \%$ saponin and $1 \%$ fetal bovine serum in PBS at $4{ }^{\circ} \mathrm{C}$ for 10 min. The cells were blocked with $3 \%$ BSA at room temperature for $30 \mathrm{~min}$ and incubated with primary antibody against p-AKT at $4{ }^{\circ} \mathrm{C}$ overnight $(0.1 \%$ saponin and $1 \%$ fetal bovine serum in PBS). Cells were washed twice in PBS, then incubated simultaneously with fluorescein isothiocyanate-labeled secondary antibody for $1 \mathrm{~h}$ at room temperature. Negative controls were prepared by incubation of the cells with anti-IgG antibody. Nucleus was stained with DAPI for 2 min. After staining, cells were rinsed 4 times with PBS and prepared for microscopic analysis. The images were captured using an immunefluorescence microscopy (Olympus).

\section{In vivo mouse metastasis models}

All animal work was conducted in accordance with a protocol approved by the Institutional Animal Care and Use Committee of Shanghai University of Traditional Chinese Medicine. Four to six weeks old female Balb/c nude mice, purchased from Sino-British
Sippr/BK Lab Animal Co, Ltd (Shanghai, China), were used for animal study. For lung metastasis study, $2 \times 10^{5}$ viable MDA-MB231-luc breast cancer cells were resuspended in PBS and subsequently injected into the lateral tail vein in a volume of $0.1 \mathrm{ml}$. Mice were randomly divided into 3 groups: (1) vehicle (1\% DMSO in PBS) group (control), (2) low-dose formononetin group (10 mg/kg), (3) high-dose formononetin group ( $20 \mathrm{mg} / \mathrm{kg}$ ). There were 10 mice per group. formononetin was administrated intraperitoneally (i.p.) every 2 days. Bioluminescent imaging was performed by anesthetizing and injecting mice retro-orbitally with $1.5 \mathrm{mg}$ of D-luciferin ( $15 \mathrm{mg} / \mathrm{ml}$ in PBS), and images were acquired at $5 \mathrm{~min}$ after injection using the Xenogen IVIS 200 system before analysis using the Living Image software (Xenogen).

\section{Statistical analysis}

All data were presented as the means \pm standard deviation (S.D.) of 3 independent experiments done in triplicate. Statistical analysis was performed by Student's $t$-test or one-way analysis of variance (ANOVA). Survival curves were analyzed according to the Kaplan-Meier method, and p-value was calculated for the comparisons between curves by the log-rank test. In all cases, $\mathrm{p}<0.05$ was considered statistically significant.

\section{Results}

$\nabla$

Cytotoxicity of formononetin to MDA-MB-231-luc cells Chemical structure of formononetin was shown in $\bullet$ Fig. 1a. To verify the effect of formononetin on cell viability, cells were treated with formononetin at indicated concentrations for $24 \mathrm{~h}$ and tested by MTT assay. Compared with untreated control cells, the viabilities of MDA-MB-231-luc and 4T1 cells were not significantly affected by formononetin at a concentration between 0 and $80 \mu \mathrm{mol} / \mathrm{l}$ ( $\odot$ Fig. 1b). Furthermore, the effect of formononetin $(0-80 \mu \mathrm{mol} / \mathrm{l})$ occurred in the absence of evident cytotoxicity, as verified by cell morphology ( $\bullet$ Fig. 1c). Thus, noncytotoxic concentration of formononetin was used in the subsequent experiments.

\section{Formononetin inhibited breast cancer cell migration and invasion}

To investigate the inhibitory effect of formononetin on migration of MDA-MB-231-luc and 4T1 cells, the wound-healing assay was performed. After incubation with formononetin for $12 \mathrm{~h}$, the number of cells migrated to the denuded zone was analyzed. The results demonstrated that formononetin suppressed migration of breast cancer cells in a dose-dependent manner. Treatment with formononetin $(2.5,5,10,20$, and $40 \mu \mathrm{mol} / \mathrm{l})$ was inhibited by $10.6,15.9,38.7,57.8$, and $75.9 \%$ of MDA-MB-231 cell migration, and by $13.0,18.8,35.4,64.8$, and $75.1 \%$ of $4 \mathrm{~T} 1$ cell migration, respectively ( $\bullet$ Fig. 2a, b). To further examine the effect of formononetin on the invasive ability of breast cancer cells, a BD chamber coated with matrigel was used. Our data showed that the number of cells invading the lower chamber was significantly reduced by formononetin and a $79.2 \%$ or $78.5 \%$ reduction in cell invasion of MDA-MB-231 or 4T1 breast cancer cell was observed for treatment with $40 \mathrm{mmol} / \mathrm{l}$ formononetin ( $\bullet$ Fig. $2 \mathrm{c}$, d). These results suggest that formononetin is effective in preventing breast cancer cell migration and invasion. 

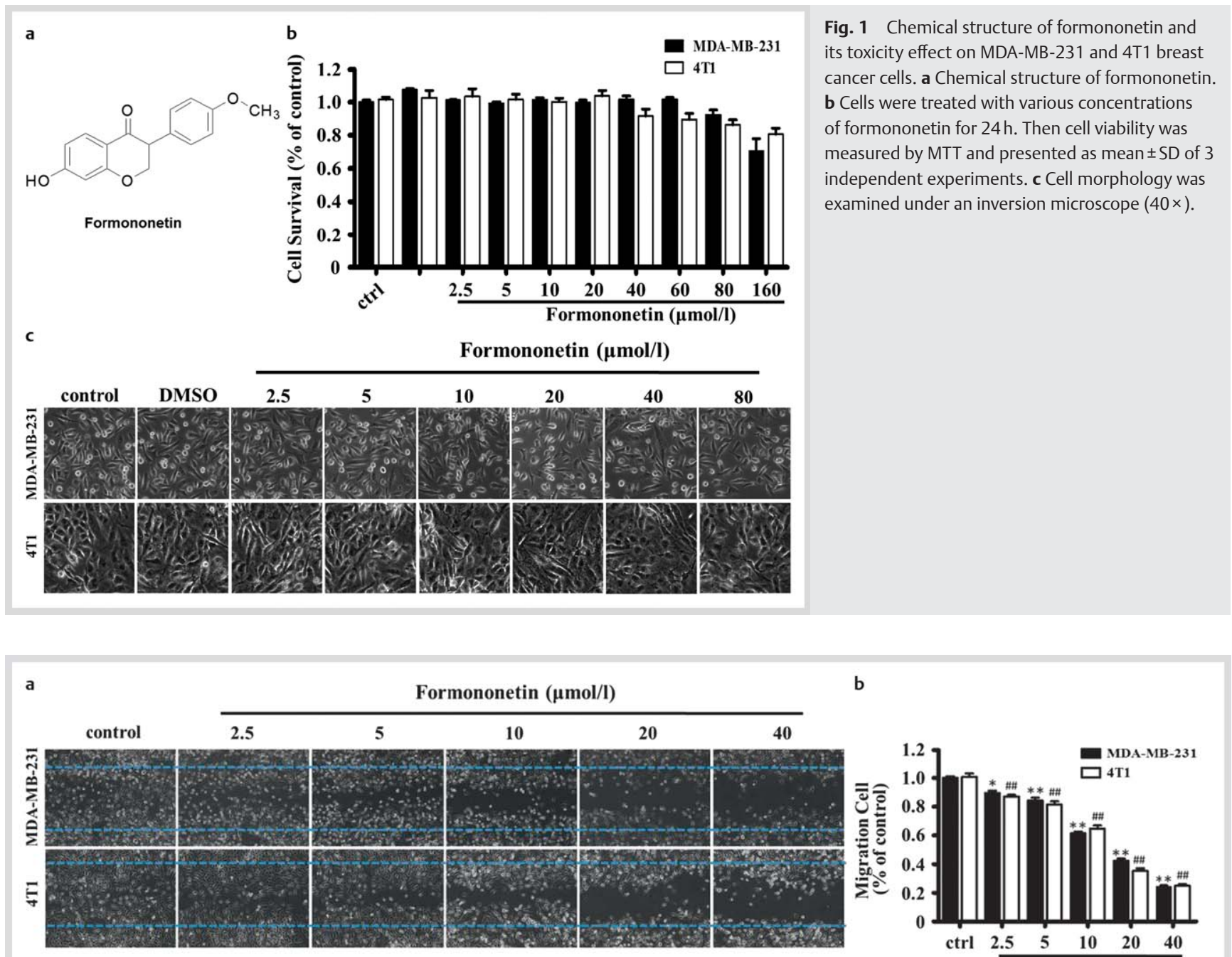

b

c

Formononetin $(\mu \mathrm{mol} / \mathrm{l})$
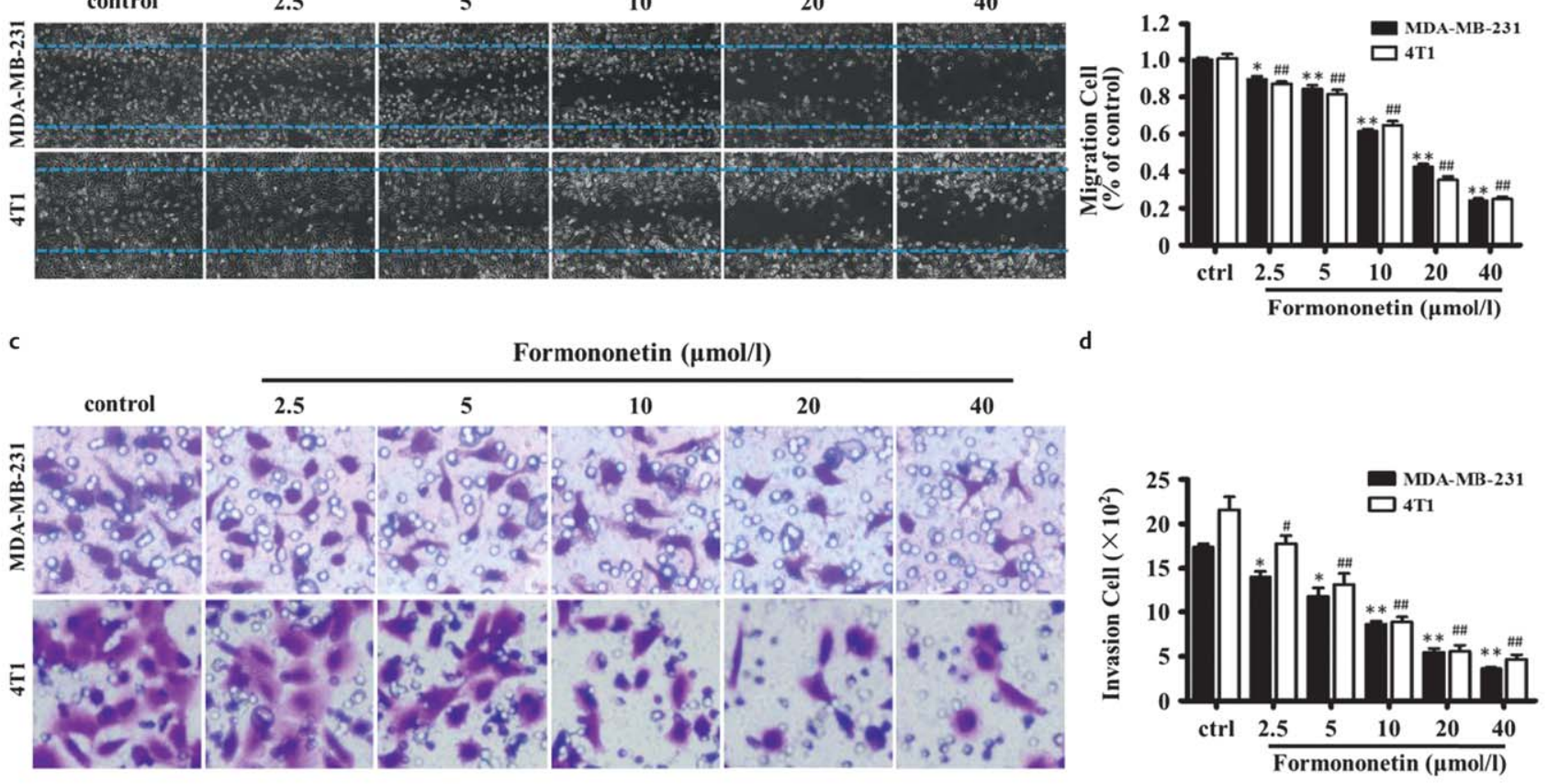

Fig. 2 Effects of formononetin on MDA-MB-231 and 4T1 breast cancer cells migration and invasion. a MDA-MB-231 and 4T1 cell monolayers were scraped by a sterile micropipette tip and the cells were treated with various concentrations of formononetin for $12 \mathrm{~h}$. Cells migrated into the wounded region were photographed $(10 \times)$. $\mathbf{b}$ The number of migration cells was quantified in 6 fields in each treatment from 3 independent experiments. The result expressed as a percentage based on the ratio of the number of migration cells to that of the controls. Data were presented as mean \pm SD. c MDA-MB- 231 and $4 T 1$ cells were treated with various concentrations of Formononetin for $12 \mathrm{~h}$ and cell invasion assay was performed. The invaded cells were photographed $(40 \times)$. $\mathbf{d}$ The invaded cells were counted in 6 random fields in each treatment, and data were calculated from 3 independent experiments and presented as mean \pm SD. ${ }^{*}$ or ${ }^{\#} \mathrm{p}<0.05,{ }^{* *}$ or ${ }^{\# \#} \mathrm{p}<0.01$, compared with the control group.

\section{Effects of formononetin on MMPs expression}

Since the expression of MMPs is crucial to extracellular matrix (ECM) degradation, which is required for cell invasion, it is vital to determine whether MMPs are involved in the inhibition of migration and invasion by formononetin. The effects of for- mononetin on MMPs were investigated by Western blot and real time-PCR. As shown in $\bullet \mathbf{F i g} . \mathbf{3 a}$, b, formononetin treatment led to a dose-dependent reduction in MMP-9 and MMP-2 expression. The results also demonstrated that formononetin elevated the expressions of TIMP-1 and TIMP-2, which were known to be 


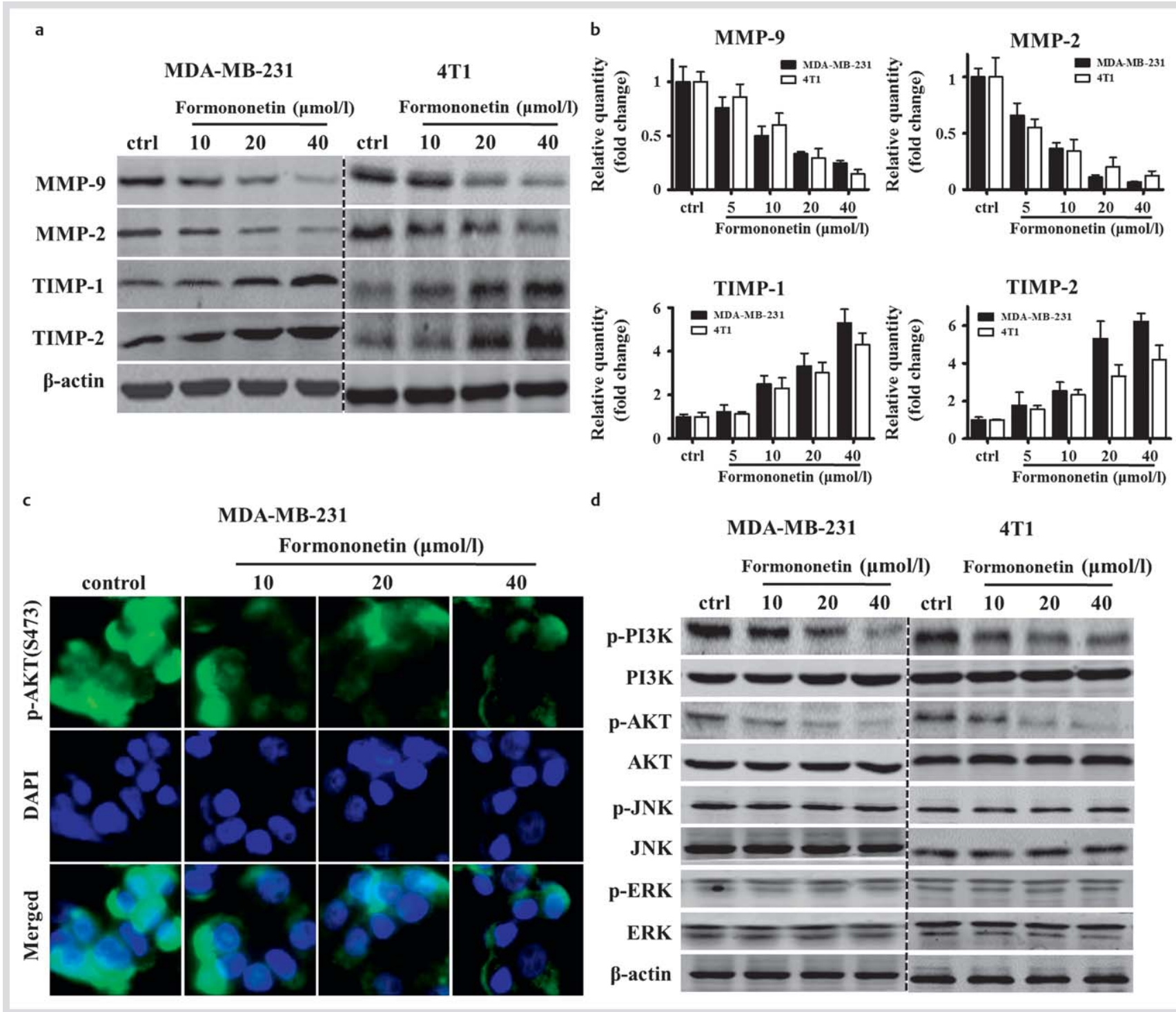

Fig. 3 Effect of formononetin on expressions of MMP-2/9, TIMP-1/2, and PI3K/AKT in breast cancer cells. MDA-MB-231 and 4T1 cells were treated with various concentrations of formononetin for $12 \mathrm{~h}$ and the expressions of MMP-9, MMP-2 and TIMP-1, TIMP-2 protein a and mRNA b were analyzed by RT-PCR and Western blotting, respectively. c MDA-MB-231 cells plated on coverslips were incubated with various concentrations of formononetin for $12 \mathrm{~h}$, and the intracellular co-localization of p-AKT was analyzed using immunofluorescence staining. Data shown here was one of 3 different experiments. $\mathbf{d}$ MDAMB-231 and 4T1 cells were incubated with various concentrations of formononetin for $12 \mathrm{~h}$, and the protein level of phospho and total PI3K, AKT, JNK, and ERK were determined.

negative regulators of MMPs. These results suggest that formononetin can affect expressions of proteins and genes involved in proteolytic activation.

\section{Effects of formononetin on the PI3K|AKT signaling pathway}

It has been reported that MMP-2 and MMP-9 expressions are critically mediated by the PI3K/Akt pathway. To investigate the effect of formononetin on the AKT in MDA-MB-231-luc cells, immunofluorescence analyses were performed. The results demonstrated that formononetin inhibited the expression of the p-AKT in a concentration-dependent manner ( $\bullet$ Fig. 3c). To confirm the data generated by immunofluorescence staining, we performed Western blot analysis of phosphorylated and totalPI3K, AKT, JNK, and ERK. Our results showed that formononetin could inhibit the expressions of p-PI3K and p-AKT in a dosedependent manner, but the levels of phospho-ERK and phos-
pho-JNK were not affected by formononetin ( $\bullet$ Fig. 3d). Taken together, all of our data suggest that formononetin suppresses the PI3K/AKT signaling pathway in breast cancer cells.

\section{Effects of formononetin on lung metastasis in vivo}

The mouse tail vein injection tumor metastasis model was used to evaluate the inhibitory effect of formononetin on MDA-MB231-luc metastasis. After tail vein injection, vehicle control or formononetin at $10 \mathrm{mg} / \mathrm{kg} / \mathrm{day}$ or $20 \mathrm{mg} / \mathrm{kg} / \mathrm{day}$ was administered. Treatment continued for 35 days after MDA-MB-231-luc cells injection, and the treatment effect of formononetin was examined by bioluminescence imaging. As shown in $\bullet$ Fig. $4 \mathbf{4 a}, \mathbf{b}$, formononetin dramatically reduced the development of lung metastases in a dose- and time-dependent manner. Photon flux in the lungs of mice treated at this dose was dramatically reduced $(\mathrm{p}<0.05$ or $\mathrm{p}<0.01$ ) compared with control ( $\bullet$ Fig. $4 \mathbf{b}$ ). Furthermore, survival analysis showed that mice receiving a 


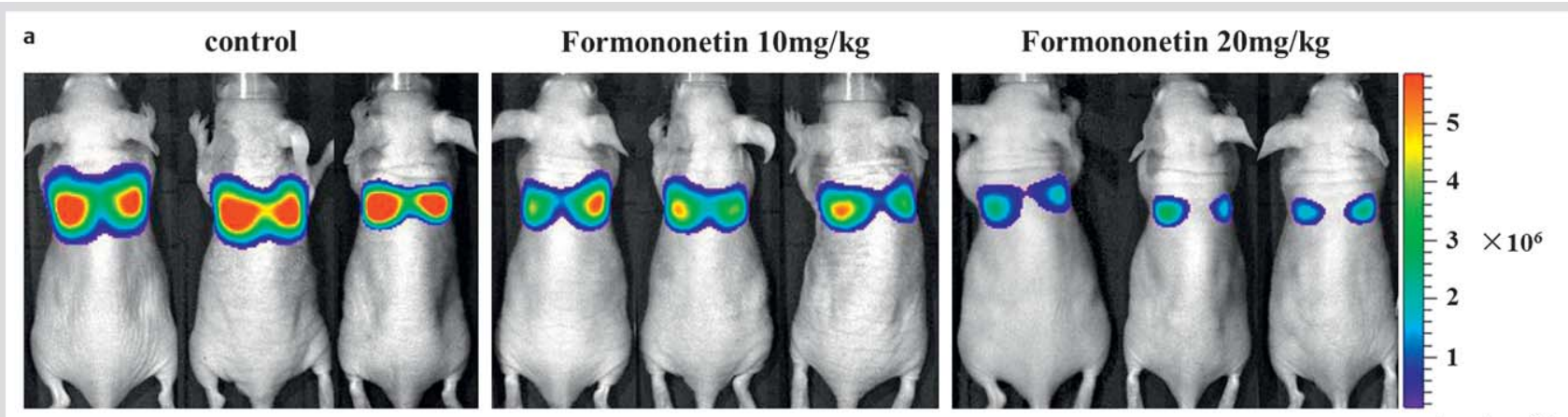

b

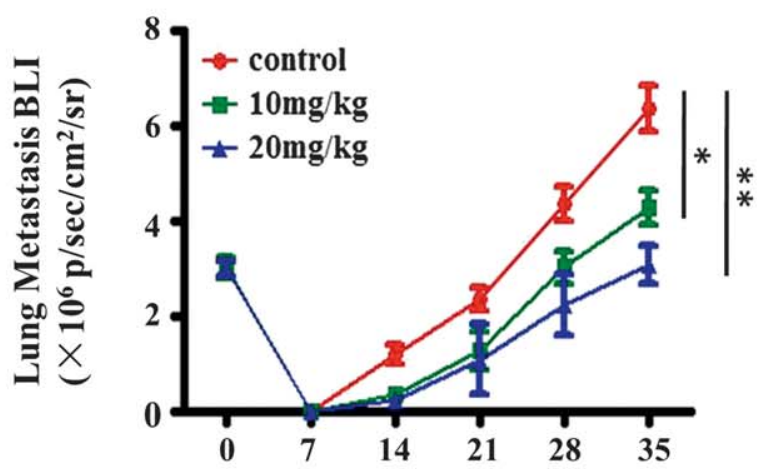

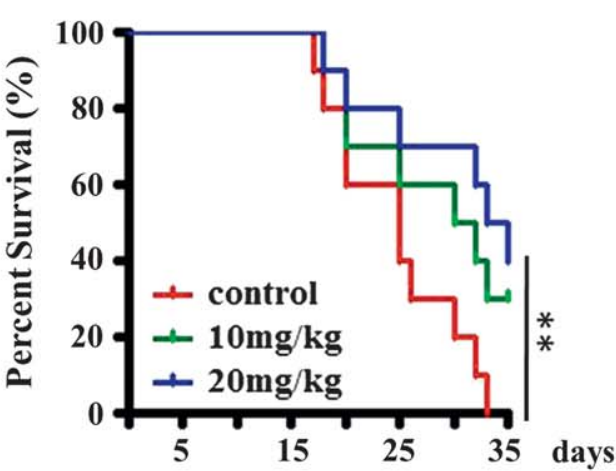

Fig. 4 Preventive effects of formononetin on mouse tail vein injection breast tumor metastasis model. a Bioluminescence imaging of lung-metastatic breast cancer cells at 5 weeks post MDA-MB- 231 breast cancer cells implantation $\left(2 \times 10^{5}\right.$ cells by tail vein injection), showing that the preventive effects of formononetin on the lung-metastasis of MDA-MB-231 breast cancer ( $\mathrm{n}=10 / \mathrm{group}) . \mathrm{p} / \mathrm{sec} / \mathrm{cm}^{2} / \mathrm{sr}=\mathrm{photons} / \mathrm{second} / \mathrm{cm}^{2} / \mathrm{steradian}$. $\mathbf{b}$ Quantitative analysis of metastatic cells in lung bioluminescence analysis. The means \pm SD are presented; ${ }^{*} p<0.05,{ }^{* *} p<0.01$. c Kaplan-Meier analysis of mouse survival after xenograft. p-Values were calculated using 2-sided log-rank test.

treatment of formononetin had a statistically significantly longer survival than the mice with vehicle control treatment (॰ Fig. 4c).

\section{Discussion}

$\nabla$

Recently, considerable emphases have been given to identify new anticancer agents from natural sources. Formononetin, a naturally existing isoflavone, has been reported to have a wide range of pharmacologic effects, such as inhibition of cell proliferation and cell cycle progression, and induction of apoptosis in various cancer cell lines [12,16-20,25]. Metastatic spread of breast cancer is responsible for $90 \%$ of human cancer-related deaths and thus remains one of the important negative predictors of breast cancer prognosis [26,27]. However, whether formononetin exerts an inhibitory effect on breast cancer metastasis has not been elucidated previously.

In the present study, we have demonstrated that formononetin strikingly inhibited the migratory and invasive abilities of breast cancer cells at noncytotoxic concentrations in vitro ( $\bullet$ Fig. 2 ). These results indicated that formononetin inhibited breast cancer cell migration and invasion, and the effect was not attributed to its cytotoxicity. In addition, we also found that formononetin inhibited breast cancer cell metastasis and prolonged animal survival time in vivo ( $\bullet$ Fig. 4). These results indicated that formononetin might play a beneficial role in breast cancer metastasis.

A vital step in cancer metastasis processes is the proteolytic degradation of the ECM by proteolytic enzymes, such as MMPs [28].
MMPs are a family of zinc-containing endopeptidases, of which MMP-2 and MMP-9 are highly expressed in aggressive breast tumors and are associated with poor clinical outcome $[5,6$, $29,30]$. The inhibition of MMP-2 and MMP-9 expressions is a critical step in the prevention of cancer metastasis [27,31-33]. TIMPs, the regulators of MMPs, are also involved in tumor progression, invasion, metastasis and angiogenesis [34]. Furthermore, increased expressions of TIMP-1 or TIMP-2 have been shown to suppress cell invasion [35-37]. In our study, it was found that the inhibition of MMP-2 and MMP-9 expressions and the increase in TIMP-1 and TIMP-2 expressions were attributable to the anti-invasive effect of formononetin ( $\bullet$ Fig. 3a, b).

Many have reported that MMP-2 and MMP-9 expression were mediated by the PI3K/Akt pathway [38-43]. PI3K is a lipid kinase that controls multiple cellular processes through AKT activation. Furthermore, AKT activation can lead to cancer invasion and metastasis by stimulating the secretion of MMPs $[39,44,45]$. The presence of phosphatidylinositol 3-kinase $\gamma$ (PI3K $\gamma$ ) overexpression is characteristic in the metastatic breast cancer cells, when compared with the normal breast epithelial cell line or nonmetastatic breast cancer cells. In addition, the overexpression of recombinant $\mathrm{PI} 3 \mathrm{~K} \gamma$ was reported to be able to increase the metastatic ability of nonmetastatic breast cancer cells [46]. Moreover, PI3K inhibitor could lead to a reduction in MMP-2 activation, cell migration and cell invasion [47]. Some traditional Chinese medicine monomers and compounds have been reported to have inhibitory effects on the migration and invasion of cancer cells via reducing the expression of MMPs via the PI3K/Akt signaling pathway [48-56]. It was also reported that formononetin inhibited the breast cancer cell proliferation by decreasing the 
expression of cyclin D1 via the IGF1/PI3K/Akt pathways [17]. In our study, we have demonstrated that treatment with formononetin significantly reduced PI3K and Akt phosphorylation ( $\odot$ Fig. 3c, d), which indicated an inhibitory effect to the PI3K/ Akt signaling pathway by formononetin. Therefore, we suggest that formononetin inhibits the invasion of breast cancer cells by reducing the expression of MMP-2 and MMP-9 through PI3K/Akt signaling pathways.

In conclusion, the present study has demonstrated that formononetin decreased the invasive ability of MDA-MB-231 and 4T1 breast cancer cells, including migration and invasion, by inhibiting MMP-2 and MMP-9 expressions. This effect might be attributed to the inactivation of PI3K/Akt pathway. These results provide new insights into molecular mechanisms involved in the anti-invasive activity of formononetin in breast cancer cells. This finding strongly suggests formononetin to be a potentially useful anti-invasive agent for breast cancers.

\section{Conflict of Interest}

\section{$\nabla$}

The authors declare that they have no conflicts of interest in the authorship or publication of this contribution.

\section{References}

1 Redig AJ, McAllister SS. Breast cancer as a systemic disease: a view of metastasis. J Intern Med 2013; 274: 113-126

2 Mahamodhossen YA, Liu W, Rong-Rong Z. Triple-negative breast cancer: new perspectives for novel therapies. Med Oncol 2013; 30: 653

3 Amos KD, Adamo B, Anders CK. Triple-negative breast cancer: an update on neoadjuvant clinical trials. Int J Breast Cancer 2012; 2012: 385978

4 Baser 0 , Wei W, Xie L, Henk HJ, Teitelbaum A. Retrospective study of patients with metastatic triple-negative breast cancer: survival, health care utilization, and cost. Comm Oncol 2012; 9: 8-14

5 Talvensaari-Mattila A, Paakko P, Hoyhtya M, Blanco-Sequeiros G, Turpeenniemi-Hujanen T. Matrix metalloproteinase-2 immunoreactive protein: a marker of aggressiveness in breast carcinoma. Cancer 1998; 83: 1153-1162

6 Pellikainen JM, Ropponen KM, Kataja VV, Kellokoski JK, Eskelinen MJ, Kosma VM. Expression of matrix metalloproteinase (MMP)-2 and MMP-9 in breast cancer with a special reference to activator protein-2, HER2, and prognosis. Clinical cancer research 2004; 10: 7621-7628

7 Li HC, Cao DC, Liu Y, Hou YF, Wu J, Lu JS, Di GH, Liu G, Li FM, Ou ZL, Jie $C$, Shen ZZ, Shao ZM. Prognostic value of matrix metalloproteinases (MMP-2 and MMP-9) in patients with lymph node-negative breast carcinoma. Breast Cancer Res Treat 2004; 88: 75-85

8 Egeblad $M$, Werb $Z$. New functions for the matrix metalloproteinases in cancer progression. Nat Rev Cancer 2002; 2: 161-174

$9 \mathrm{Li}$ W, Sun YN, Yan XT, Yang SY, Kim S, Lee YM, Koh YS, Kim YH. Flavonoids from Astragalus membranaceus and their inhibitory effects on LPS-stimulated pro-inflammatory cytokine production in bone marrow-derived dendritic cells. Arch Pharm Res 2014; 37: 186-192

$10 \mathrm{Ma} \mathrm{Z}$, Ji W, Fu Q Ma S. Formononetin Inhibited the Inflammation of LPS-Induced Acute Lung Injury in Mice Associated with Induction of PPAR Gamma Expression. Inflammation 2013; 36: 1560-1566

11 Lai PK, Chan JY, Cheng L, Lau CP, Han SQ, Leung PC, Fung KP, Lau CB. Isolation of anti-inflammatory fractions and compounds from the root of Astragalus membranaceus. Phytother Res 2013; 27: 581-587

12 Ren J, Xu HJ, Cheng H, Xin WQ Chen X, Hu K. Synthesis and antitumor activity of Formononetin nitrogen mustard derivatives. Eur J Med Chem 2012; 54: 175-187

13 Ji ZN, Zhao WY, Liao GR, Choi RC, Lo CK, Dong TT, Tsim KW. In vitro estrogenic activity of Formononetin by two bioassay systems. Gynecological endocrinology: the official journal of the International Society of Gynecol Endocrinol 2006; 22: 578-584

14 Park J, Kim SH, Cho D, Kim TS. Formononetin, a phyto-oestrogen, and its metabolites up-regulate interleukin-4 production in activated $\mathrm{T}$ cells via increased AP-1 DNA binding activity. Immunology 2005; 116: $71-81$
15 Sun T, Wang J, Huang LH, Cao YX. Antihypertensive effect of Formononetin through regulating the expressions of eNOS, 5-HT2A/1B receptors and alpha1-adrenoceptors in spontaneously rat arteries. Eur J Pharmacol 2013; 699: 241-249

16 Ye Y, Hou R, Chen J, Mo L, Zhang J, Huang Y, Mo Z. Formononetininduced apoptosis of human prostate cancer cells through ERK1/2 mitogen-activated protein kinase inactivation. Horm Metab Res 2012; 44: 263-267

17 Chen J, Zeng J, Xin M, Huang W, Chen X. Formononetin induces cell cycle arrest of human breast cancer cells via IGF1/PI3K/Akt pathways in vitro and in vivo. Horm Metab Res 2011; 43: 681-686

18 Chen J, Sun L. Formononetin-induced apoptosis by activation of Ras/ p38 mitogen-activated protein kinase in estrogen receptor-positive human breast cancer cells. Horm Metab Res 2012; 44: 943-948

19 Mansoor TA, Ramalho RM, Luo X, Ramalhete C, Rodrigues CM, Ferreira $M J$. Isoflavones as apoptosis inducers in human hepatoma HuH-7 cells. Phytother Res 2011; 25: 1819-1824

20 Auyeung KK, Law PC, Ko JK. Novel anti-angiogenic effects of Formononetin in human colon cancer cells and tumor xenograft. Oncol Rep 2012; 28: 2188-2194

21 Krenn L, Paper DH. Inhibition of angiogenesis and inflammation by an extract of red clover (Trifolium pratense L.). Phytomedicine 2009; 16: $1083-1088$

22 Chavez KJ, Garimella SV, Lipkowitz S. Triple negative breast cancer cell lines: one tool in the search for better treatment of triple negative breast cancer. Breast Dis 2010; 32: 35-48

23 Heppner GH, Miller FR, Shekhar PM. Nontransgenic models of breast cancer. Breast Cancer Res 2000; 2: 331-334

24 Tao K, Fang M, Alroy J, Sahagian GG. Imagable 4T1 model for the study of late stage breast cancer. BMC Cancer 2008; 8: 228

25 Tyagi AM, Srivastava K, Singh AK, Kumar A, Changkija B, Pandey R, Lahir $S$, Nagar GK, Yadav DK, Maurya $R$, Trivedi $R$, Singh $D$. Formononetin reverses established osteopenia in adult ovariectomized rats. Menopause (New York, NY) 2012; 19: 856-863

26 Scully OJ, Bay BH, Yip G, Yu Y. Breast cancer metastasis. Cancer Genom Proteom 2012; 9: 311-320

27 Alix-Panabieres C, Muller V, Pantel K. Current status in human breast cancer micrometastasis. Curr Opin Oncol 2007; 19: 558-563

28 Deryugina EI, Quigley JP. Matrix metalloproteinases and tumor metastasis. Cancer Metas Rev 2006; 25: 9-34

29 Jezierska A, Motyl T. Matrix metalloproteinase-2 involvement in breast cancer progression: a mini-review. Med Sci Mon 2009; 15: RA32RA40

30 Vizoso FJ, Gonzalez LO, Corte MD, Rodriguez JC, Vazquez J, Lamelas ML, Junquera S, Merino AM, Garcia-Muniz JL. Study of matrix metalloproteinases and their inhibitors in breast cancer. Brit J Cancer 2007; 96: 903-911

31 Hua J, Muschel RJ. Inhibition of matrix metalloproteinase 9 expression by a ribozyme blocks metastasis in a rat sarcoma model system. Cancer research 1996; 56: 5279-5284

32 Kondraganti S, Mohanam S, Chintala SK, Kin Y, Jasti SL, Nirmala C, Lakka SS, Adachi Y, Kyritsis AP, Ali-Osman F, Sawaya R, Fuller GN, Rao $J S$. Selective suppression of matrix metalloproteinase-9 in human glioblastoma cells by antisense gene transfer impairs glioblastoma cell invasion. Cancer research 2000; 60: 6851-6855

33 Iurlaro $M$, Loverro $G$, Vacca A, Cormio G, Ribatti D, Minischetti M, Ria $R$, Bruno $M$, Selvaggi L. Angiogenesis extent and expression of matrix metalloproteinase- 2 and -9 correlate with upgrading and myometrial invasion in endometrial carcinoma. Eur J Clin Invest 1999; 29: 793-801

34 Cruz-Munoz W, Khokha R. The role of tissue inhibitors of metalloproteinases in tumorigenesis and metastasis. Crit Rev Clin Lab Sci 2008; 45: 291-338

35 Khokha $R$. Suppression of the tumorigenic and metastatic abilities of murine B16-F10 melanoma cells in vivo by the overexpression of the tissue inhibitor of the metalloproteinases-1. J Nat Cancer Inst 1994; 86: 299-304

36 Khokha R, Zimmer MJ, Graham CH, Lala PK, Waterhouse P. Suppression of invasion by inducible expression of tissue inhibitor of metalloproteinase-1 (TIMP-1) in B16-F10 melanoma cells. J Nat Cancer Inst 1992; 84: 1017-1022

37 Valente P, Fassina G, Melchiori A, Masiello L, Cilli M, Vacca A, Onisto M, Santi L, Stetler-Stevenson WG, Albini A. TIMP-2 over-expression reduces invasion and angiogenesis and protects B16F10 melanoma cells from apoptosis. Int J Cancer 1998; 75: 246-253 
38 Chen JS, Wang $Q$ Fu XH, Huang XH, Chen XL, Cao LQ Chen LZ, Tan HX, Li W, Bi J, Zhang $L J$. Involvement of PI3K/PTEN/AKT/mTOR pathway in invasion and metastasis in hepatocellular carcinoma: Association with MMP-9. Hepatol Res 2009; 39: 177-186

39 Li X, Yang Z, Song W, Zhou L, Li Q, Tao K, Zhou J, Wang X, Zheng Z, You N, Dou K, Li H. Overexpression of Bmi-1 contributes to the invasion and metastasis of hepatocellular carcinoma by increasing the expression of matrix metalloproteinase (MMP)2, MMP-9 and vascular endothelial growth factor via the PTEN/PI3K/Akt pathway. Int J Oncol 2013; 43: 793-802

40 Tian T, Nan KJ, Guo H, Wang WJ, Ruan ZP, Wang SH, Liang X, Lu CX. PTEN inhibits the migration and invasion of HepG2 cells by coordinately decreasing MMP expression via the PI3K/Akt pathway. Oncol Rep 2010; 23: 1593-1600

41 Qiu Q Yang M, Tsang BK, Gruslin A. EGF-induced trophoblast secretion of MMP-9 and TIMP-1 involves activation of both PI3K and MAPK signalling pathways. Reproduction 2004; 128: 355-363

42 Ye B, Jiang $L L, X u H T$, Zhou DW, Li ZS. Expression of PI3K/AKT pathway in gastric cancer and its blockade suppresses tumor growth and metastasis. Int J Immunopathol Pharmacol 2012; 25: 627-636

43 Huang CY, Fong YC, Lee CY, Chen MY, Tsai HC, Hsu HC, Tang CH. CCL5 increases lung cancer migration via PI3K, Akt and NF-kappaB pathways. Biochem Pharmacol 2009; 77: 794-803

44 Zhang ZJ, Ma SL. miRNAs in breast cancer tumorigenesis (Review). Oncol Rep 2012; 27: 903-910

45 Jung CH, Kim EM, Park JK, Hwang SG, Moon SK, Kim WJ, Um HD. Bmal1 suppresses cancer cell invasion by blocking the phosphoinositide 3-kinase-Akt-MMP-2 signaling pathway. Oncol Rep 2013; 29: 2109-2113

46 Xie Y, Abel PW, Kirui JK, Deng C, Sharma P, Wolf DW, Toews ML, Tu Y. Identification of upregulated phosphoinositide 3-kinase gamma as a target to suppress breast cancer cell migration and invasion. Biochem Pharmacol 2013; 85: 1454-1462

47 Karam AK, Santiskulvong C, Fekete M, Zabih S, Eng C, Dorigo O. Cisplatin and PI3kinase inhibition decrease invasion and migration of human ovarian carcinoma cells and regulate matrix-metalloproteinase expression. Cytoskeleton 2010; 67: 535-544
48 Chen J, Lan T, Hou J, Zhang J, An Y, Tie L, Pan Y, Liu J, Li X. Atorvastatin sensitizes human non-small cell lung carcinomas to carboplatin via suppression of AKT activation and upregulation of TIMP-1. Int J Biochem Cell Biol 2012; 44: 759-769

49 Ko HS, Lee HJ, Kim SH, Lee EO. Piceatannol suppresses breast cancer cell invasion through the inhibition of MMP-9: involvement of PI3K/AKT and NF-kappaB pathways. J Agric Food Chem 2012; 60: 4083-4089

50 Lee H, Kim JS, Kim E. Fucoidan from seaweed Fucus vesiculosus inhibits migration and invasion of human lung cancer cell via PI3K-Akt-mTOR pathways. PloS One 2012; 7: e50624

51 Hsieh CY, Tsai PC, Chu CL, Chang FR, Chang LS, Wu YC, Lin SR. Brazilein suppresses migration and invasion of MDA-MB-231 breast cancer cells. Chemicobiol Interact 2013; 204: 105-115

52 Tang L, Ma X, Tian Q, Cheng Y, Yao H, Liu Z, Qu X, Han X. Inhibition of angiogenesis and invasion by DMBT is mediated by downregulation of VEGF and MMP-9 through Akt pathway in MDA-MB-231 breast cancer cells. Food Chem Toxicol 2013; 56: 204-213

53 Tong B, Lu D, Wei Z, Wang T, Xia Y, Dai Y. Gleditsioside B, a triterpene saponin isolated from the anomalous fruits of Gleditsia sinensis Lam., abrogates bFGF-induced endothelial cell migration through preventing the activation of MMP-2 and FAK via inhibiting ERK and PI3K/AKT signaling pathways. Vascul Pharmacol 2013; 58: 118-126

54 Yan KH, Lee LM, Yan SH, Huang HC, Li CC, Lin HT, Chen PS. Tomatidine inhibits invasion of human lung adenocarcinoma cell A549 by reducing matrix metalloproteinases expression. Chemico-biological interactions 2013; 203: 580-587

55 Chen SM, Liu JL, Wang X, Liang C, Ding J, Meng LH. Inhibition of tumor cell growth, proliferation and migration by X-387, a novel active-site inhibitor of mTOR. Biochem Pharmacol 2012; 83: 1183-1194

56 Li M, Wu S, Liu Z, Zhang W, Xu J, Wang Y, Liu J, Zhang D, Tian H, Li Y, Ye $W$. Arenobufagin, a bufadienolide compound from toad venom, inhibits VEGF-mediated angiogenesis through suppression of VEGFR-2 signaling pathway. Biochem Pharmacol 2012; 83: 1251-1260 